\title{
Atypical chromosome abnormalities in acute myeloid leukemia type M4
}

\author{
Agnes C. Fett-Conte ${ }^{1}$, Roseli Viscardi Estrela ${ }^{2}$, Cristina B. Vendrame-Goloni ${ }^{3}$, Andréa B. Carvalho-Salles ${ }^{1}$, \\ Octávio Ricci-Júnior ${ }^{4}$ and Marileila Varella-Garcia ${ }^{5}$ \\ ${ }^{1}$ Departamento de Biologia Molecular, Faculdade de Medicina de São José do Rio Preto, \\ São José do Rio Preto, SP, Brazil. \\ ${ }^{2}$ Austa Hospital, São José do Rio Preto, SP, Brazil. \\ ${ }^{3}$ Departamento de Biologia, Instituto de Biociências, Letras e Ciências Exatas, \\ Universidade Estadual Paulista, São José do Rio Preto, SP, Brazil. \\ ${ }^{4}$ Hemocentro, São José do Rio Preto, SP, Brazil. \\ ${ }^{5}$ Comprehensive Cancer Center, University of Colorado, Denver, CO, USA.
}

\begin{abstract}
This study reports an adult AML-M4 patient with atypical chromosomal aberrations present in all dividing bone marrow cell at diagnosis: $t(1 ; 8)(p 32.1 ; q 24.2)$, der(9)t(9;10)(q22;?), and ins(19;9)(p13.3;q22q34) that may have originated transcripts with leukemogenic potential.
\end{abstract}

Key words: acute myeloid leukemia, chromosomal abnormalities, chromosomal translocations.

Received: February 10, 2006; Accepted: June 22, 2006.

Acute non-lymphocytic or myelogenous leukemia (ANLL or AML) represents a hematopoietic malignancy characterized by abnormal cell proliferation and stalled differentiation leading to the accumulation of immature cells in the marrow itself, in peripheral blood and eventually in other tissues. Primary chromosomal abnormalities in AML are highly specific and considered to be associated with leukemic transformation, whereas secondary changes are less specific and probably contribute to disease progression. As reviewed by Chen and Sandberg. (2002), the common chromosomal abnormalities in the acute myelomonocytic leukemia FAB (French-American-British Cooperative Group) type M4 include monosomy 5 or del(5q), monosomy 7 or del(7q), trisomy 8 , t $(6 ; 9)$ (p23;q34), and rearrangements involving the Mixed Lineage Leukemia $(M L L)$ gene mapped at $11 \mathrm{q} 23$ [del(11) (q23); t(9;11)(p22;q23), t(11;19)(q23;p13)], and Core Binding Factor B (CBFß) mapped at 16q22 [del(16)(q22), $\operatorname{inv}(16)(\mathrm{p} 13 \mathrm{q} 22), \mathrm{t}(16 ; 16)(\mathrm{p} 13 ; \mathrm{q} 22)]$. Less frequently, trisomy 4 , trisomy $22, \mathrm{t}(8 ; 21)(\mathrm{q} 22 ; \mathrm{q} 22)$ and rearrangements with breakpoints in $3 \mathrm{q} 21,3 \mathrm{q} 26,8 \mathrm{p} 11,11 \mathrm{p} 15$ and $11 \mathrm{q} 13$ have also been reported in FAB M4 type patients

Send correspondence to Agnes Cristina Fett-Conte. Departamento de Biologia Molecular, Faculdade de Medicina de São José do Rio Preto, Av. Brigadeiro Faria Lima 5416, Bairro Universitário, 15090000 São José do Rio Preto, SP, Brazil. E-mail: genetica@ famerp.br.
(Mitelman Database of Chromosome Aberration in Cancer 2006). Karyotype is generally an important prognostic factor in AML, a favorable prognosis being associated with minor karyotypic changes, low frequency of abnormal bone marrow cells and changes specifically involving the $C B F \beta$ gene, while a poor prognosis is associated with a monosomy 5 , monosomy 7 , trisomy 8 , abnormalities in the $3 \mathrm{q}$ andchanges specifically involving the $M L L$ gene (Strout et al., 1999; Chen and Sandberg, 2002). Atypical cytogenetic findings have been sporadically reported in AMLM4 but the scarcity of these abnormalities poses a challenge to using such changes as prognostic factors, reinforcing the need for the collection of clinical data on rare events.

In this paper we describe an adult male patient diagnosed with hematological and clinical characteristics of AML-M4 who presented good response to treatment. Cytogenetic analyses revealed atypical structural aberrations not previously described in AML-M4 that could only be properly identified using G-banding, spectral karyotyping (SKY) and metaphase fluorescence in situ hybridization (FISH) analyses.

Bone marrow aspirate withdrawn at diagnosis of the disease was used for classical and molecular cytogenetic analysis after a 24-h non-stimulated culture in RPMI1640 medium with $20 \%$ fetal calf serum. G-banding (20 cells) and spectral SKY analyses (10 cells) were performed as de- 
scribed in Vendrame-Goloni et al. (2003) and the karyotypes were described according to the International System for Human Cytogenetic Nomenclature (ISCN, 2005). The metaphase FISH assays were performed according to a standard protocol (Estécio et al., 2002) and used the TelVysion $8 \mathrm{q}$ and the LSI C-MYC probes labeled with SpectrumOrange (Vysis/Abbott Laboratories) and a 4-cosmid contig mapped just centromeric to theTFP3 (E2A) gene (Boomer et al., 2001) which was labeled with SpectrumGreen.

The patient was a 32-year-old man who presented to the Austa Hospital (São José do Rio Preto, São Paulo state, Brazil) in October 2000 with fever, petechiae, cough and fatigue. He had no hepatosplenomegaly or lymph node enlargement but his hemogram showed pancytopenia, with $8.2 \mathrm{~g} / \mathrm{dL}$ of hemoglobin, a hematocrit of $25.3 \%$ and a white blood cell count of $2 \times 10^{9} / \mu \mathrm{L}$ ( $8 \%$ neutrophils, $41 \%$ lymphocytes and $46 \%$ blast cells). A bone marrow aspirate showed hypercelullarity with $78 \%$ of myeloblasts and monocyte lineage cells. Cytochemical tests showed 44\% Sudan-Black positive and 10\% periodic acid Schiff (PAS) positive blast cells and $32 \%$ of non-erythroid blast cells were positive for non-specific alpha-naphylacetate esterase. The patient reported no previous exposure to cytotoxic or mutagenic agents. The diagnosis of de novo acute myeloid leukemia FAB classification type M4 was made. This study was approved by the ethics committee of the IBILCE-UNESP, São José do Rio Preto, SP, Brazil.

Cytogenetic analysis using G-banding showed structural changes interpreted as two reciprocal translocations, $\mathrm{t}(1 ; 8)(\mathrm{p} 32 ; \mathrm{q} 24)$ and $\mathrm{t}(9 ; 19)(\mathrm{q} 22 ; \mathrm{p} 13)$, in the 20 cells analyzed.Independent SKY analysis detected four abnormal chromosomes [i.e. $\operatorname{del}(1)(\mathrm{p} 32), \operatorname{der}(8) \mathrm{t}(1 ; 8)(\mathrm{p} 32.1 ; \mathrm{q} 24.2)$, $\operatorname{der}(9) \mathrm{t}(9 ; 10)(\mathrm{q} 22 ; ?)$ and $\operatorname{der}(19) \mathrm{t}(9 ; 19)(\mathrm{q} 22 ; \mathrm{p} 13.3)]$ in the 10 cells analyzed by this technique (Figure 1A). These findings were supported by the metaphase FISH studies performed using the C-MYC, TelVysion 8q and 19p13.3 contig probes. The TelVysion probe recognized homology with the normal $8 \mathrm{q}$ and with the terminal region of the short arm of the chromosome designated as $\operatorname{del}(1)(\mathrm{p} 32)$ in the SKY analysis (Figures 1B, C), therefore confirming the reciprocal translocation $\mathrm{t}(1 ; 8)$ detected by G-banding analysis. The $M Y C$ gene sequence was also detected in the der(1), indicating that the $8 \mathrm{q} 24$ breakpoint was proximal to this gene (Figure 1D). The 19p13.3 contig probe recognized homology with the distal region of the p-arm of the normal chromosome 19 and the end of the rearranged arm of the abnormal chromosome 19, distal to the material identified as originating from chromosome 9 (Figures 1B, C). Therefore, the chromosome postulated previously to be $\operatorname{der}(19) \mathrm{t}(9 ; 19)$ was identified as an ins(19;9)(p13.3; 22 q34) with the breakpoint proximal to the TFPT $(E 2 A)$ gene. On the basis of all the tests (summarized in Figure 1E), the patient's karyotype was interpreted as $46, \mathrm{XY}, \mathrm{t}(1 ; 8)$ (p32.1;q24.2), $\operatorname{der}(9) \mathrm{t}(9 ; 10)(\mathrm{q} 22 ; ?), \quad \operatorname{ins}(19 ; 9)(\mathrm{p} 13.3 ; \mathrm{q} 22$ q34).

The patient was submitted to remission-induction chemotherapy with $100 \mathrm{mg} / \mathrm{m}^{2} /$ day of intravenous cytosine arabinoside (ara-C) continuously for 7 days and $12 \mathrm{mg} / \mathrm{m}^{2} /$ day of intravenous idarubicin for 2 days. Complete remission was achieved after the first course of induction chemotherapy. The patient then received three courses of consolidation chemotherapy consisting of $2 \mathrm{mg} / \mathrm{m}^{2} /$ day of ara-C for 4 days and $45 \mathrm{mg} / \mathrm{m}^{2} /$ day of doxorubicin for 2 days followed by non-related allogeneic bone marrow transplantation. The patient has remained disease-free as at January 2006.

Clinical descriptions of atypical cytogenetic cases are rare but can be useful for clinicians. An inv(4)(p14q27) was described as the sole karyotypic anomaly at diagnosis in the bone marrow from an adult patient who responded poorly to chemotherapy and had a short survival time (Benasayag et al., 2002).

At the time of the AML-M4 diagnosis our patient presented a karyotype with three atypical clonal abnormalities, $\mathrm{t}(1 ; 8)(\mathrm{p} 32.1 ; \mathrm{q} 24.2)$, der(9)t(9;10)(q22;?), and ins(19;9) (p13.3;q22q34). Interestingly, these abnormalities involved four breakpoints (1p32, 8q24.2, 9q22, and 19p13.3) reported as being disrupted in a few AML M4 cases. Of these breakpoints the $9 \mathrm{q} 22$ breakpoint has most often been reported to be involved in anomalies, although in the majority of patients it has occurred in association with other major changes (Strout et al., 1999) such as $\mathrm{t}(8 ; 21)(\mathrm{q} 22 ; \mathrm{q} 22)$, $\mathrm{t}(12 ; 19)(\mathrm{p} 11 ; \mathrm{p} 11), \mathrm{t}(16 ; 21)(\mathrm{p} 11 ; \mathrm{q} 22)$, del(11(q23) and del(12)(p11). In the literature, only three AML-M4 patients have shown single deletions involving this region. The 9 q22 regionharbors numerous potential leukemogenic genes, such as the HEMGN (EDAG) gene which is sequentially expressed at active hematopoietic sites and downregulated during the differentiation of blood cells (Yang et al., 2001) and the NOR-1 (NRA3) gene which is an 'orphan member' of the nuclear hormone receptor superfamily implicated in cell proliferation, differentiation and T-cell apoptosis, although the mechanisms controlling transcriptional activation, coactivator recruitment and agonistmediated activation still remain obscure (Laflamme et al., 2003).

The other three breakpoints (1p32, 8q24.2 and 19p13.3) detected in our patient have been less frequently reported in AML-M4. Deletions and translocations involving $1 \mathrm{p} 32$ are common in T-ALL (T-cell acute lymphoblastic leukemia) but only three AML-M4 cases are listed in the Cancer Genome Anatomy Project (Mitelman Database of Chromosome Aberration in Cancer 2006; Strout et al., 1999), two with $\mathrm{t}(1 ; 11)(\mathrm{p} 32 ; \mathrm{q} 23)$ and one with $\mathrm{t}(1 ; 21)$ (p32;q22). Numerous genes clustered at $1 \mathrm{p} 32$ are potential candidates in leukemogenesis, among them the TAL1 gene (Perotti et al., 1999; Carlotti et al., 2002) and the AF1P gene which was investigated in one of the AML-M4 pa- 

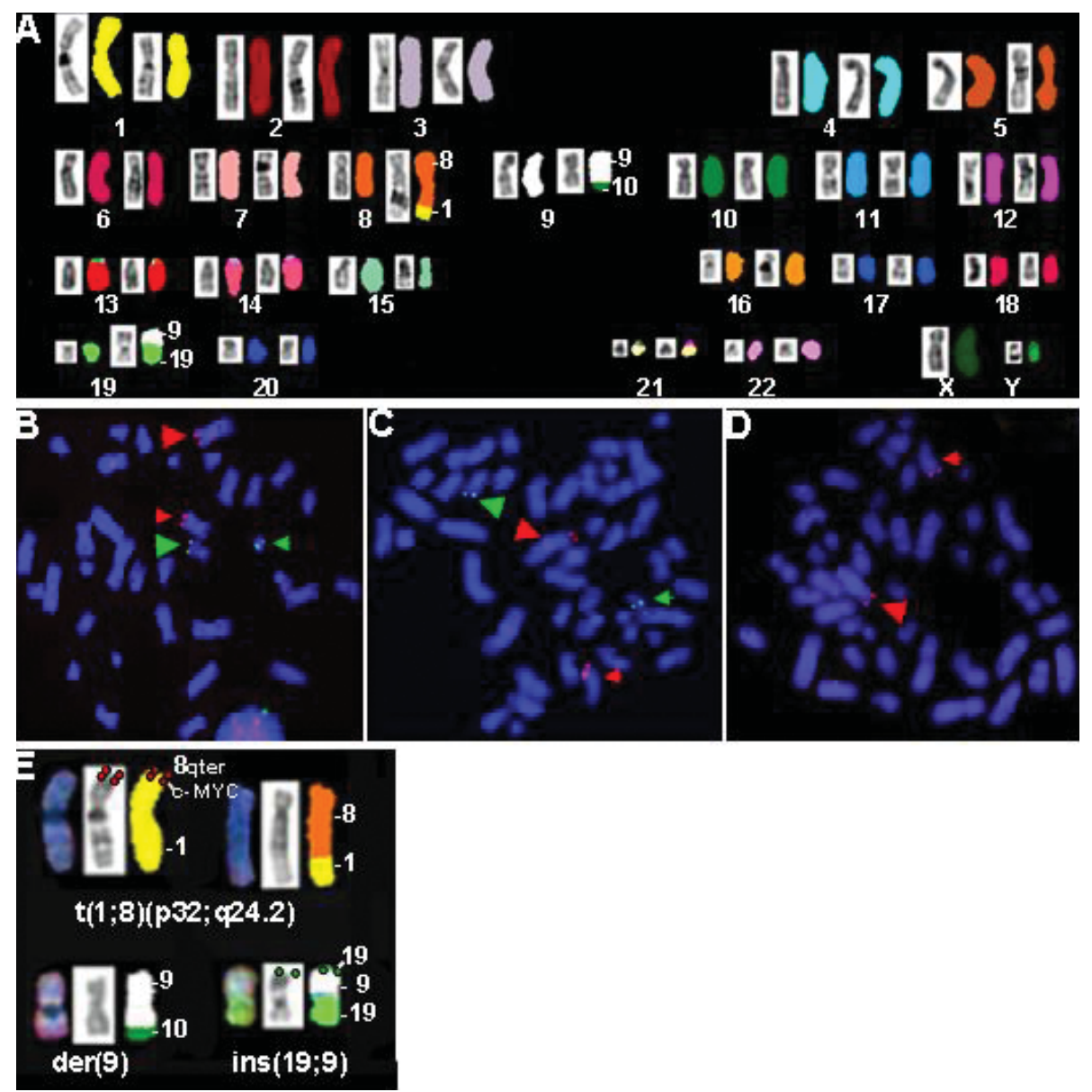

Figure 1 - Spectral karyotype (SKY) of leukemia cells from our patient at diagnosis of the disease. (A) Cell howing the band (left) and the classified (right) profiles for each chromosome. (B and C) Metaphases hybridized with the TelVysion 8q probe (labeled in red) and the 19p13.3 cosmid (labeled in green). Small arrows indicated the normal chromosomes 8 and 19 while large arrows indicate $\operatorname{der}(1) t(1 ; 8)$ and ins(19;9)(p13.3;q22q24). These results suggest that $\mathrm{t}(1 ; 8)$ is reciprocal and the breakpoint at $19 \mathrm{p} 13$ is proximal to the TCF3 (E2A) gene. (D). Metaphase hybridized with the C-MYC probe (labeled in red). The small arrow indicates the normal chromosome 8 and the large arrow indicates der(1)t $(1 ; 8)$. These results indicate that the $8 \mathrm{q}$ breakpoint is proximal to the C-MYC locus in 8q24. (E). Montage illustrating the three clonal structural abnormalities suggested by the G-banding, SKY and metaphase FISH analyses.

tients (Cherry et al., 2001). Breakpoints at 8q24.2, in association with multiple chromosome abnormalities have been reported in two AML M4 patients(Strout et al.1999) and may affect the expression of the $M Y C$ oncogene. In our patient, the $M Y C$ gene was confirmed as translocated to the derivative chromosome 1 , but specimens from the patient were not available for protein expression assessment. Abnormalities involving chromosome band 19p13.3 are common in ALL and AML. The chromosome 19 insertion breakpoint was proximal to TFPT (TCF3, E2A) which suggested that the MLLT1 (ENL) gene could be a target for disruption. The MLLT1 gene has been causally related to leukemias including AML-M4 (Strout et al.,1999; Rubnitz and Look, 1998; Brambillasca et al., 2001; Kopf and Miskin, 2005). All these structural abnormalities are potentially associated with deregulation of genes playing key roles in cell proliferation and differentiation, either by juxtaposing these genes to constitutively active foreigner promoters or producing fusion transcripts with leukemogenic potential. However the nature of the specific gene(s) altered in our patient remains unknown.

In conclusion, our study indicates that a combination of techniques was essential to reveal cryptic chromosome rearrangements in this leukemia patient. Importantly, despite presenting a complex karyotype, which is recognized as poor prognostic factor in leukemia (Chen and Sandberg, 2002; Ferrant et al., 1997), the patient showed an excellent response to treatment and has remained in remission for over 5 years.

\section{Acknowledgments}

The study was partially supported by a United States National Institute of Health-National Cancer Institute contract grant CA 46934 to the University of Colorado Comprehensive Cancer Center and by funding from the Brazilian institutions BAP (Bolsa de Auxílio à Pesquisa) da Faculdade de Medicina de São José do Rio Preto 
(FAMERP) and the Brazilian Federal agency Coordenação de Aperfeiçoamento de Pessoal de Nível Superior (CAPES).

\section{References}

Benasayag S, Arias E, Baialardo E, Reyes M, Sapia S, Bistmans A and Slavutsky I (2002) $\operatorname{Inv}(4)(p 14 q 27)$ in a case with de novo acute nonlymphocytic leukemia. Acta Haematol 108:39-42.

Boomer T, Varella-Garcia M, Mc Gavran L, Meltesen L, Olsen AS and Huger SP (2001) Detection of E2A translocations in leukemias via fluorescence in situ hybridization. Leukemia 15:95-102.

Brambillasca F, Mosna G, Ballabio E, Biondi A, Boulukos KE and Privitera E (2001) Promoter analysis of TFPT (FB1), a molecular partner of TCF3 (E2A) in childhood acute lymphoblastic leukemia. Biochem Biophys Res Commun 288:1250-1257.

Carlotti E, Pettenella F, Amaru R, Slater S, Lister TA, Barbui T, Basso G, Cazzaniga G, Rambaldi A and Biondi A (2002) Molecular characterization of a new recombination of the SIL/TAL-1 locus in a child with T-cell acute lymphoblastic leukaemia. Br J Haematol 118:1011-1018.

Chen Z and Sandberg AA (2002) Molecular cytogenetic aspects of hematological malignacies: Clinical implications. Am J Med Genet 115:130-141.

Cherry AM, Charles DB, Jones P, Hall S and Natkunam Y (2001) A unique AML1 (CBF1A) rearrangement, $\mathrm{t}(1 ; 21)(\mathrm{p} 32 ; \mathrm{q} 22)$, observed in a patient with acute myelomonocytic leukemia. Cancer Genet Cytogenet 129:155-160.

Estécio MRH, Fett-Conte AC, Varella-Garcia M, Cíntia Fridman C and Silva AE (2002) Molecular and cytogenetic analyses on Brazilian youths with pervasive developmental disorders. J Autism Dev Disord 32:35-42.

Ferrant A, Labopin M, Frassoni F, Prentice HG, Cahn JY, Blaise D, Reiffers J, Visani G, Sanz MA, Boogaerts MA, Löwenberg B and Gorin NC (1997) Karyotype in acute myeloblastic leukemia: Prognostic significance for bone marrow transplantation in first remission: An European group for blood and marrow transplantation study. Blood 90:29312938.

ISCN (2005) An International System for Human Cytogenetic Nomenclature. Shaffer LG and Tommerup N (ed), S. Karger, Basel, 130 pp.

Kopf E and Miskin R (2005) A RUNX/AML-binding motif residing in a novel 13-bp DNA palindrome may determine the expression of the proximal promoter of the human uPA gene. J Thromb Haemost. 3:2057-2064.

Laflamme C, Filion C, Bridge JÁ, Ladanyi M, Goldring MB and Labelle Y (2003) The homeotic protein Six3 is a coactivator of the nuclear receptor NOR-1 and a corepressor of the fusion protein EWS/NOR-1 in human extraskeletal myxoid chondrosarcomas. Cancer Res 63:449-454.

Mitelman Database of Chromosome Aberrations in Cancer (2006) Mitelman F, Johansson B and Mertens F (eds), http://cgap.nci.nih.gov/Chromosomes/Mitelman.

Perotti D, Pettenella F, Luksch R, Giardini R, Gambirasio F, Ferrari D, Fossati-Bellani F and Biondi A (1999) Molecular analysis of $1 \mathrm{p} 32$ genetic involvement in pediatric T-cell non-Hodgkin's. Hematologica 84:110-113.

Rubnitz E and Look AT (1998) Molecular genetics of childhood leukemias. J Hematol Oncol 20:1-11.

Strout MP, Marcucci G, Caligiuri MA and Bloomfield CD (1999) Core-binding factor $(\mathrm{CBF})$ and MLL-associated primary acute myeloid leukemia: Biology and clinical implications. Ann Hematol 78:251-264.

Vendrame-Goloni CB, Varella-Garcia M, Carvalho-Salles AB, Ruiz MA, Ricci Júnior O and Fett-Conte AC (2003) Translocation $(11 ; 19)(\mathrm{q} 23 ; \mathrm{p} 13.3)$ associated with a novel $\mathrm{t}(5 ; 16)$ $(\mathrm{q} 13 ; \mathrm{q} 22)$ in a patient with acute myelocytic leukemia. Cancer Genet Cytogenet 141:71-74.

Yang LV, Nicholson RH, Kaplan J, Galy A and Li L (2001) Hemogen is a novel nuclear factor specifically expressed in mouse hematopoietic development and its human homologue EDAG maps to chromosome 9q22, a region containing breakpoints of hematological neoplasms. Mech Dev 104:105-111.

Associate Editor: Peter L. Pearson 